\title{
Green manure effects on inorganic nitrogen dynamics in soil and its accumulation in grape must
}

\author{
Roberto Zanzotti ${ }^{1 *}$, and Enzo Mescalchin ${ }^{1}$ \\ ${ }^{1}$ Centro di Trasferimento Tecnologico, Fondazione Edmund Mach, 38010 San Michele all'Adige, Italy
}

\begin{abstract}
The adoption of green manure practices in organic agriculture is increasingly spreading. This work aims to prove whether winter green manure - when compared to a traditional mineral fertilizer- alters the dynamics of inorganic nitrogen $\left(\mathrm{NO}_{3}{ }^{-}\right.$and $\left.\mathrm{NH}_{4}{ }^{+}\right)$availability in soil and the yeast assimilable nitrogen (YAN) in grape musts. During a two-year period, the soil nitrogen content was influenced by climatic trend and, especially, by rainfall. In fact, rainy periods reduced inorganic nitrogen availability in the soil. In both years, the green manure plot presented higher soil content of inorganic nitrogen at fruit-set, while different dynamics were shown over the following phenological phases. The must YAN concentration did not differ among treatments over the twoyear experiment.
\end{abstract}

\section{Introduction}

The green manure practice is becoming reaffirmed over recent years as a good alternative to perennial cropping, in the balancing of annual humus losses [1]. The input due to grass cover is not sufficient to level off the organic matter balance [2].

In addition to humus contribution, green manure plays an important role in improving the soil structure, thanks to the root system of the sown species and because it promotes the establishment of bacterial populations secreting stabilizing substances. This practice not only improves the soil's ability to retain water and nutrients, but also supplies nourishment to the plants through the degradation of the mulched grasses [3].

Researches carried out in the Trento province (Trentino-Alto Adige region) show that green manure contributes to increases in microbial diversity in the soil, especially bacterial taxa involved in the nitrogen cycle (i.e. Microvirga sp., Pontibacter sp. e Nitrospira sp.) [4, 5].

If green manure adds relevant benefits to the maintenance of soil fertility and biodiversity, its relationship with grapevine productivity and must composition should not be disregarded. According to some authors, cover crops can account for anthropogenic inputs and enhance yield capacity [6].

During the first transition year from conventional (inorganic fertilization) to organic management where green manure was used, no important variations in the grapevine vegetative and productive parameters were noticeable [7]. Actually, an excessive devigoration could occur, causing problems with the maintenance of vine capacity and adequate yields [8].
Nevertheless, both a decrease of yeast assimilable nitrogen (YAN) in musts and the occurrence of related vinification issues are appreciable [7]. It is still unclear whether the plant nitrogen uptake, especially during blooming and veraison when clusters are the main sinks [9], corresponds to the inorganic nitrogen release in soil provided by green manure.

The winter cover crop mixture used in the vineyard (Poaceae vs Fabaceae) affects inorganic nitrogen availability in the soil.

Barley, in relation to clover, reduces inorganic nitrogen availability affecting the YAN falloff and the free-amino acid must composition [10].

Nitrogen metabolism and its absorption dynamics in the grapevine are well known and modeled [9, 11]. Three stages are attributed to an intense plant nitrogen demand: the first one starts two weeks before blooming and can last for about six weeks, the second one occurs at veraison, and the third one takes place from harvest until leaf fall $[12,13]$.

A study about long-term fertilization on Riesling [13], highlights that nitrogen dosage and application time affect several properties related to grapevine yield and must composition. An ammonium nitrate supply at budbreak results in a $\mathrm{NO}_{3}{ }^{-}$peak in soil at fruit-set. When nitrogen is applied at fruit-set, the highest amount of $\mathrm{NO}_{3}{ }^{-}$is found at veraison, improving grape maturity and must composition [13].

This work aims to compare the effects of winter green manure and inorganic fertilization on soil inorganic nitrogen availability (expressed as the sum of $\mathrm{NO}_{3}^{-}$and $\mathrm{NH}_{4}^{+}$), and its accumulation in grape must (as YAN).

*Corresponding author: roberto.zanzotti@,fmach.it 


\section{Materials and methods}

The trial was carried out over a two-year period (20162017) in a vineyard owned by the Fondazione Edmund Mach (San Michele all'Adige, Trento, Italy). Riesling (clone GM 198/10) was grafted on an SO4 rootstock and trained on the "simple pergola trentina" system $(2.80 \mathrm{~m}$ x $0.5 \mathrm{~m})$. Soil analysis revealed a silty texture $(44 \%$ sand, $46 \%$ silt and $10 \%$ clay), a total limestone content of $532 \mathrm{~g} / \mathrm{kg} \mathrm{CaCO} \mathrm{Ca}_{3}$ with $11 \mathrm{~g} / \mathrm{kg}$ representing the active fraction and an organic matter percentage of 3.7.

The vineyard is partitioned in two plots where different management protocols have been applied since autumn 2011. According to the experimental plan, on the first lot, permanent sward is set and inorganic fertilization (IN) is provided yearly, at the end of March, by supplying $36 \mathrm{~N}$ units/ha*year of NPK 12-12-17 complex. In the second plot, a winter green manure (GM) is applied in the postharvest period. Soil is prepared by using a spring-tooth harrows at $15 \mathrm{~cm}$ depth, and seeding mixture (47\% Poaceae, 40\% Fabaceae, $13 \%$ Brassicaceae and Boraginaceae) is sowed by hand at the dose of about $180 \mathrm{~kg} / \mathrm{ha}$ and seeds are covered by coarser harrowing. In the first decade of June (Poaceae at medium milk stage, Fabaceae with $20 \%$ of pods ripe, Brassicaceae fully ripe and Boraginaceae in bloom) mulch tillage is performed by using a mulcher. Green manure yield, expressed as dry matter per surface unit, was $0.70 \mathrm{~kg} / \mathrm{m}^{2}$ in 2016 and $0.91 \mathrm{~kg} / \mathrm{m}^{2}$ in 2017 in relation to the perennial crop outcomes being 0.34 and $0.27 \mathrm{~kg} / \mathrm{m}^{2}$, respectively.

Samples for the inorganic nitrogen analysis [14] in soil was collected between rows at two depths (0-20 and 20-40 cm). 5 soil replicates per treatment and depth were collected 6 times, from the grapevine's phenological stage $\mathrm{BBCH} 16-17$ to 93 [15] in 2016 and from 53 to 92 in 2017. At grape technological maturity, growth and yield parameters (listed in Table 1) were recorded for 6 vines corresponding to the soil sampling areas. After that, all bunches from the same vines were sampled in order to determine the YAN and the main constituting parameters of musts through an infrared spectroscopy FT-IR (Grapescan 2000, FOSS, Hillerød, Denmark). Rainfall data were downloaded from the Fondazione Edmund Mach agrometeorology website.

Data were analyzed by factorial ANOVA and Tukey test $(\mathrm{p}<0.05)$ using the software STATISTICA 13 Dell Inc.

\section{Results}

During the two-year experiment, nitrogen dynamics in the soil varied depending on the year and weather conditions. In accordance with rainy periods, inorganic nitrogen (inorg.-N) concentration in the soil tended to decrease (Figure 1, 2). According to the factorial ANOVA performed separately for each sampling time, significant differences were highlighted between treatments, but not between depths. In both years, the inorganic nitrogen content in the soil of the green manure treatment was higher in correspondence with the second sampling (end blooming/beginning of fruit-set).
Later, the annual dynamics differentiated and, in 2016 (Figure 1) the fertilizer treatment showed constantly higher inorganic nitrogen concentration from veraison to harvest $(\mathrm{BBCH} 83-89)$. Treatments did not differ when the inorganic nitrogen in soil was determined in postharvest.

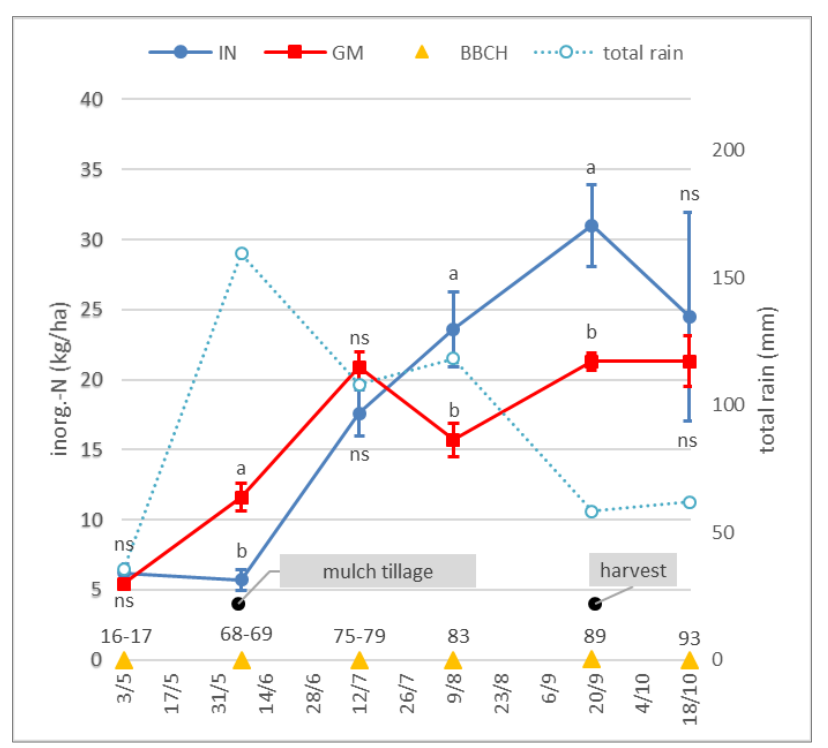

Fig. 1. Inorganic nitrogen (inorg.-N) release dynamics in the 0$40 \mathrm{~cm}$ soil layer (average $\pm \mathrm{SE}$ ) as a function of the fertilization strategy (mineral fertilizer IN, green manure GM) and sum of the precipitation (total rainfall) between two consecutive soil samplings in 2016. Within each sampling, different letters point out significant differences according to Tukey test at $\mathrm{p}<0.05$.

In 2017, the total rainfall (Apr.-Oct., $738 \mathrm{~mm}$ ) was higher than 2016 (Apr.-Oct., $569 \mathrm{~mm}$ ) and, at the onset of ripening, the higher inorganic nitrogen values were recorded in the green manure treatment. This could be explained through the buffer effect provided from the green manure mineralization compared to the leaching of the mineral fertilization. Later, in both parcels, the inorganic nitrogen concentration in soil set between 10 and $15 \mathrm{~kg} /$ ha showing no significant difference (Figure 2). This $\mathrm{N}$ concentration decrease could be attributed to an intensification of the total rainfall occurring between the fourth and the fifth samplings. 


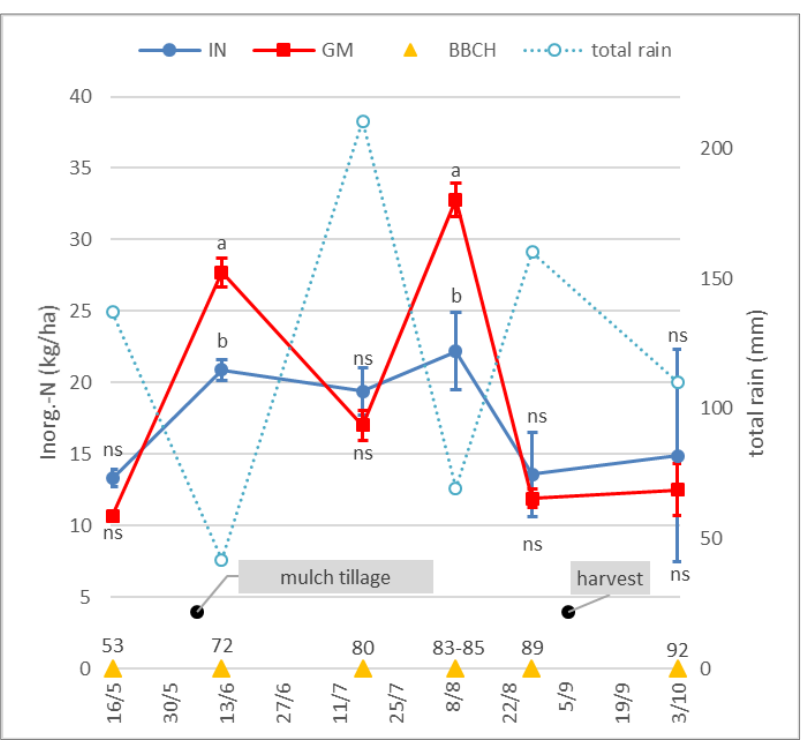

Fig. 2. Inorganic nitrogen (inorg.-N) release dynamics in the 0$40 \mathrm{~cm}$ soil layer (average $\pm \mathrm{SE}$ ) as a function of the fertilization strategy (mineral fertilizer IN, green manure GM) and sum of the precipitation (total rainfall) between two consecutive soil samplings in 2017. Within each sampling, different letters point-out significant differences according to Tukey test at $\mathrm{p}<0.05$.

Regarding the growth and yield performance of the grapevines (Table 1), over the two year period (20162017) no statistical differences were recorded about shoot number per plant, yield, cluster weight, cluster/shoot rate and Ravaz index. In 2016 and 2017, the number of clusters per vine was significantly higher in the green manure plot (20.5 and 21.8 respectively vs 19.5 and 19.8, table 1) and in 2017 the same trend occurred regarding the pruning weight per vine $(0.38$ for IN vs 0.45 for GM).

Table 1. Growth and yield data of Riesling grapevines from inorganic fertilization (IN) and green manure (GM) treatment, in 2016 and 2017. Within each year, different letters point-out significant differences according to Tukey test at $\mathrm{p}<0.05$.

\begin{tabular}{|l|c|c|c|c|}
\hline Year & \multicolumn{2}{|c|}{2016} & \multicolumn{2}{c|}{2017} \\
\hline Treatment & IN & GM & IN & GM \\
\hline Nr. of samples & 30 & 30 & 30 & 30 \\
\hline Shoots/vine & 10.0 & 9.3 & 11.3 & 11.0 \\
\hline Clusters/vine & $19.5 \mathrm{~b}$ & $20.5 \mathrm{a}$ & $19.8 \mathrm{~b}$ & $21.8 \mathrm{a}$ \\
\hline Yield/plant (kg) & 2.50 & 2.74 & 1.75 & 2.00 \\
\hline Cluster weight (g) & 130 & 135 & 90 & 94 \\
\hline Cluster/shoot & 1.9 & 2.2 & 1.7 & 2.0 \\
\hline Pruning weight/vine (kg) & 0.38 & 0.39 & $0.38 \mathrm{~b}$ & $0.45 \mathrm{a}$ \\
\hline Ravaz index & 7.0 & 7.6 & 5.3 & 4.7 \\
\hline
\end{tabular}

The must composition (Table 2) in 2016 did not differ among treatments for any parameter considered as part of the trial. In 2017, in the green manure treatment, higher concentrations of sugar content (Brix), $\mathrm{pH}$, tartaric acid and potassium were recorded. In 2016 and 2017, the YAN values were similar for the two treatments. According to several authors, these values are lower than the deficiency threshold $[16,17]$. A linear regression for both years, excluding the last post-harvest sampling, was performed. The model between YAN and inorganic nitrogen (YAN $=2.7891$ *inorg. $-\mathrm{N}+62.65)$ is not significant $\left(\mathrm{R}^{2}=0.118, \mathrm{p}=0.138\right)$. When performing a separated linear regression for 2016 and 2017, a yeardependent effect was highlighted. Only in 2016, the model was significant $(\mathrm{YAN}=8.7415 *$ inorg. $-\mathrm{N}-29.79$, $\left.\mathrm{R}^{2}=0.543, \mathrm{p}=0.015\right)$ while in $2017 \mathrm{R}^{2}$ value is 0.074 and $\mathrm{p}$ value is 0.436 .

Table 2. Must composition from inorganic fertilization (IN) and green manure (GM) treatments in 2016 and 2017. Within each year, different letters point-out significant differences according to Tukey test at $\mathrm{p}<0.05$.

\begin{tabular}{|l|c|c|c|c|}
\hline Year & \multicolumn{2}{|c|}{2016} & \multicolumn{2}{c|}{2017} \\
\hline Plot & IN & GM & IN & GM \\
\hline Nr. of samples & 5 & 5 & 5 & 5 \\
\hline Brix & 20.1 & 20.4 & $19.5 \mathrm{~b}$ & $20.1 \mathrm{a}$ \\
\hline pH & 3.28 & 3.23 & $3.08 \mathrm{~b}$ & $3.18 \mathrm{a}$ \\
\hline $\begin{array}{l}\text { Titratable acidity } \\
\text { g/L) }\end{array}$ & 6.20 & 6.70 & 7.28 & 8.14 \\
\hline Tartaric acid (g/L) & 8.78 & 8.89 & $7.10 \mathrm{~b}$ & $9.27 \mathrm{a}$ \\
\hline Malic acid (g/L) & 2.07 & 2.21 & 3.18 & 3.01 \\
\hline Potassium (g/L) & 1.86 & 1.83 & $1.39 \mathrm{~b}$ & $1.80 \mathrm{a}$ \\
\hline YAN (mg/L) & 112 & 106 & 108 & 118 \\
\hline
\end{tabular}

\section{Conclusions}

In this two-year comparison, the yeast assimilable nitrogen in musts from treatments subjected to green manure and inorganic fertilization did not differ. Worthy of attention are a year-effect and a seasonal nitrogen soil content which fluctuates greatly if compared with the relative stable YAN in musts.

In both years, the green manure treatment reached the higher inorganic nitrogen contents at blooming beginning of fruit-set, matching with one of the most intense nitrogen demand of the grapevine for the translocation to leaves and clusters. At veraison, the second moment of high nitrogen requirements from the soil (because of its accumulation in the berries), the two treatments followed different trends in the biennium. Despite the different nitrogen release dynamics from the soil, the YAN content in musts was not significantly affected. In this trial, the green manure practice enabled a production of musts with equal YAN contents in comparison with those obtained from the plot where 36 $\mathrm{kg} \mathrm{N} /$ ha*year were supplied. 
Further research is needed to determine whether the green manure practices, in contrast with inorganic fertilization, affect the amino acid composition of musts, and thus the potential aromatic profile of wines.

Acknowledgments are owed to Gugole Silvia, the Unità Trasformazione e Conservazione FEM and to the Azienda Agricola FEM.

\section{References}

1. E. Mescalchin. R. Zanzotti. Inf. Agr.. 22. 50-53 (2018).

2. E. Mescalchin. R. Zanzotti. M. Gobber. D. Bertoldi. F. Toniolli. L. Conte. L'Enol.. 5, 75-80 (2014).

3. E. Costantini. Supp. Not. ERSA., 16-22 (1994).

4. C. M. O. Longa. L. Nicola. L. Antonielli. E. Mescalchin. R. Zanzotti. E. Turco. I. Pertot. J. Appl. Microb. 123, 1547-1560 (2017).

5. C. A. Ingels. K. M. Scow. D. A. Whisson. R. E. Drenovsky. Am. J. Enol. Vitic. 56, 19-29 (2005).

6. R. A. Wittwer. B. Dorn. W. Jossi. M. G. A. van der Heijden. Sci. Rep. 7. 41911 (2017).

7. E. Mescalchin. R. Zanzotti. M. Secchi. D. Bertoldi. R. Larcher. M. Malacarne. T. Román. G. Nicolini. 18th International Symposium GiESCO. 1047-1051 (2013).

8. C.A. Ingels. Cover Cropping in Vineyards: A Grower's Handbook. (University of California, Division of Agriculture and Natural Resources, Oakland, 1998).

9. B. Wermelinger. International Symposium on Nitrogen in Grapes and Wine. 23-30 (1991).

10. E. P. Pérez-Álvarez. T. Garde-Cerdán. P. Santamaría. E. García-Escudero. F. Peregrina. Plant Soil. 390, 143-156 (2015).

11. K. A. Roubelakis-Angelakis. W. M. Kliewer. Horticultural Reviews. 14, 407-439 (1992).

12. W. J. Conradie. S. Afr. J. Enol. Vitic. 1, 59-65 (1980).

13. A. W. Linsenmeier. U. Loos. O. Löhnertz. Am. J. Enol. Vitic. 59, 255-264 (2008).

14. VDLUFA. Methodenbuch I. (VDLUFA-Verlag, Darmstadt, 2002).

15. D. H. Lorenz. K.W. Eichhorn. H. Bleiholder. R. Klose. U. Meier. E. Weber. Aust. J. Grape Wine Res. 1, 100-103 (1995).

16. G. Nicolini. R. Larcher. G. Versini. Vitis. 43, 89-96 (2004).

17. V. Jiranek. $12^{\text {th }}$ Int. Oenol. Symp. 80-96 (1999). 